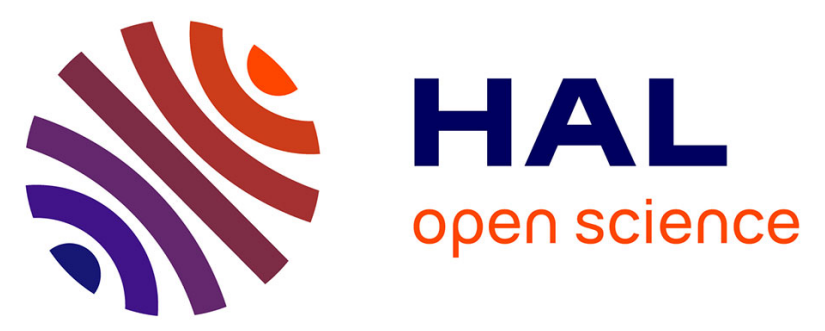

\title{
The proteolytic processing of the serine protease matriptase-2: identification of the cleavage sites required for its autocatalytic release from the cell surface
} Marit Stirnberg, Eva Maurer, Angelika Horstmeyer, Sonja Kolp, Stefan Frank, Tobias Bald, Katharina Arenz, Andreas Janzer, Kai Prager, Patrick Wunderlich, et al.

\section{To cite this version:}

Marit Stirnberg, Eva Maurer, Angelika Horstmeyer, Sonja Kolp, Stefan Frank, et al.. The proteolytic processing of the serine protease matriptase-2: identification of the cleavage sites required for its autocatalytic release from the cell surface. Biochemical Journal, 2010, 430 (1), pp.87-95. 10.1042/BJ20091565 . hal-00506520

\section{HAL Id: hal-00506520 \\ https://hal.science/hal-00506520}

Submitted on 28 Jul 2010

HAL is a multi-disciplinary open access archive for the deposit and dissemination of scientific research documents, whether they are published or not. The documents may come from teaching and research institutions in France or abroad, or from public or private research centers.
L'archive ouverte pluridisciplinaire HAL, est destinée au dépôt et à la diffusion de documents scientifiques de niveau recherche, publiés ou non, émanant des établissements d'enseignement et de recherche français ou étrangers, des laboratoires publics ou privés. 


\title{
The proteolytic processing of the serine protease matriptase-2: identification of the cleavage sites required for its autocatalytic release from the cell surface
}

\author{
Marit STIRNBERG*1, Eva MAURER*, Angelika HORSTMEYER*, Sonja KOLP*, Stefan \\ FRANK*, Tobias BALD*, Katharina ARENZ*, Andreas JANZER*, Kai PRAGER $\dagger$, \\ Patrick WUNDERLICH ${ }^{\dagger}$, Jochen WALTER $\uparrow$ and Michael GÜTSCHOW*
}

\author{
*Pharmaceutical Institute, University of Bonn, An der Immenburg 4, 53121 Bonn, Germany, \\ $\uparrow$ Department of Neurology, University of Bonn, Sigmund-Freud-Str. 25, 53127 Bonn, Germany. \\ ${ }^{1}$ To whom correspondence should be addressed (email marit.stirnberg@uni-bonn.de).
}

Short title: Cell surface shedding of matriptase-2

\begin{abstract}
Matriptase-2 is a member of the type II transmembrane serine proteases (TTSPs), an emerging class of cell surface proteases involved in tissue homeostasis and several human disorders which exhibit a domain organization similar to other TTSPs, with a cytoplasmic $\mathrm{N}$-terminus, a transmembrane domain and an extracellular C-terminus containing the non-catalytic stem region and the protease domain. To gain further insight into the biochemical functions of matriptase-2, we characterized subcellular localizations of complexed and uncomplexed forms and identified cell surface shedding as a hallmark in the proteolytic processing of matriptase-2. Using HEK293 cells stably transfected with cDNA encoding human matriptase-2, we demonstrate cell membrane localization of an inactive, single-chain zymogen. Membrane-associated matriptase- 2 is highly $\mathrm{N}$-glycosylated and occurs in monomeric as well as multimeric forms that are covalently linked by disulfide bonds. Furthermore, matriptase-2 undergoes shedding into the conditioned medium as an activated, two-chain form containing the catalytic domain which is cleaved at the canonical activation motif but linked to a released portion of the stem region via a conserved disulfide bond. Cleavage sites were identified by mass spectrometry, sequencing and mutational analysis. Interestingly, cell surface shedding and activation of a matriptase-2 variant bearing a mutation at the active site serine is dependent on the catalytic activity of co-expressed or co-incubated wild type matriptase-2, indicating a transactivation and transshedding mechanism.
\end{abstract}

Key words: type II transmembrane serine protease, proteolytic processing, activation, cell surface shedding, cleavage site determination, mass spectrometry

Abbreviations used: BCIP, 5-bromo-4-chloro-3-indolyl phosphate; CUB, complement factor $\mathrm{C} 1 \mathrm{~s} / 1 \mathrm{r}$, urchin embryonic growth factor, bone morphogenetic protein; DAPI, 4',6'-diamidino-2-phenylindole; DMEM, Dulbecco's modified Eagle's medium; FBS, fetal bovine serum; HEK, human embryonic kidney cells 293; IRIDA, iron-refractory iron deficiency anemia; LDLRA, low density lipoprotein receptor class A; NBT, nitro tetrazolium blue chloride; MT2, matriptase-2; PNGase F, N-glycosidase F; SEA, sea urchin sperm protein, enteropeptidase, agrin; TMPRSS6, transmembrane protease, serine 6; TTSPs, type II transmembrane serine proteases. 


\section{INTRODUCTION}

Matriptase-2 (also known as TMPRSS6) was identified in 2002 [1] and belongs to the type II transmembrane serine proteases (TTSPs) representing a recently described family of cell surface proteinases [2-8]. Structurally, this enzyme consists of a short cytoplasmic amino terminal tail, a transmembrane domain, a stem region containing a SEA (sea urchin sperm protein, enteropeptidase, agrin) domain, two CUB (complement factor $\mathrm{C} 1 \mathrm{~s} / 1 \mathrm{r}$, urchin embryonic growth factor, bone morphogenetic protein) domains and three LDLRA (low density lipoprotein receptor class A) domains, and a carboxy terminal serine protease domain.

Matriptase-2 shares high similarity with matriptase (MT-SP1), which is extensively characterized. Matriptase is expressed by a number of epithelial cells and is overexpressed in different human cancers [3,9-13]. Substrates of matriptase are proteins located at the cell surface or in the extracellular matrix, with a major importance in the complex process of tumor invasion and angiogenesis [14-17]. Interestingly, in contrast to matriptase, overexpression of matriptase- 2 significantly suppresses breast and prostate cancer growth and reduced levels of matriptase- 2 correlate with poor patient outcome $[12,13]$.

Compared to matriptase, matriptase- 2 has a more limited expression pattern. TMPRSS6 mRNA can be found predominantly in liver, suggesting tissue-specific functions $[1,18]$. Indeed, the role of matriptase-2 as a key regulator in iron homeostasis was identified very recently and described in two independent studies $[18,19]$. Mutations in matriptase-2 were directly linked to the inability to downregulate high levels of hepcidin [18-20], the systemic regulator of iron homeostasis, leading to iron-refractory iron deficiency anemia (IRIDA). Matriptase-2 was described to suppress hepcidin expression $[19,20]$ by cleaving bone morphogenetic protein co-receptor hemojuvelin [21].

Matriptase is synthesized as an inactive, single-chain, membrane-bound polypeptide and undergoes complex proteolytic processing during zymogen activation [22-24]. A cleavage after Gly ${ }^{149}$ within a conserved motif of the SEA domain splits matriptase into two fragments [23]. However, this cleaved matriptase appears to remain membrane-associated via non-covalent linkage $[23,25,26]$. Transactivation in which the intrinsic, weak proteolytic activity from one zymogen molecule activates another occurs afterwards by proteolytic cleavage between $\mathrm{Arg}^{614}$ and $\mathrm{Val}^{615}$ within the canonical activation motif $\mathrm{Arg}^{614}$ Val-Val-Gly-Gly converting the inactive, single-chain zymogen into the disulfide-linked, two-chain protease (activated form) [23,27]. As a consequence of a conserved disulfide bond [22], the catalytic domain of matriptase remains attached to the propeptide after activation cleavage representing a general feature of TTSPs [28-30]. Lastly, matriptase is released from the cell surface via ectodomain shedding by proteolytic cleavage after Lys $^{189}$ or Lys $^{204}$ in a complex with its cognate inhibitor, i.e. hepatocyte growth factor activator inhibitor-1 (HAI-1) [22,31].

In contrast to matriptase, molecular mechanisms involved in the activation and proteolytic processing of matriptase- 2 are largely unknown. Recent publications demonstrate that mutations of matriptase- 2 affecting regions other than the catalytic domain of patients with IRIDA may have a profound influence on the activity of the protease [32-34]. Based on the presence of a conserved disulfide bond linking the pro- and catalytic domains, the catalytic domain of matriptase- 2 might also remain membrane-bound following activation. However, soluble forms of matriptase- 2 were detected in the conditioned medium of transfected cells that were not further specified [21,32,34,35].

In the present study, we demonstrate efficient cell surface shedding of matriptase- 2 into the conditioned media of transfected cells. Importantly, shed matriptase- 2 was detected in a two-chain form that was highly active. In contrast, cell-associated matriptase- 2 was predominantly present as an inactive, single-chain zymogen. We were able to isolate the shed, activated, two-chain form and identified the cleavage site between $\mathrm{Arg}^{437}$ and $\mathrm{Val}^{438}$ (numbering based on protein GenBank entry CAC85953) within the second CUB domain of the non-catalytic stem region. This processing site was confirmed by 
mutational analysis which revealed a second cleavage site after $\operatorname{Arg}^{404}$ important for the release of matriptase-2. Furthermore, mutation of the catalytic active $\operatorname{Ser}^{753}$ blocked shedding and activation of matriptase-2 whereas both processing events occurred in the presence of wild type matriptase-2, indicating a trans-mechanism of enzyme activation and release from the cell surface.

\section{EXPERIMENTAL}

\section{Cell lines and culture conditions}

Human embryonic kidney cells (HEK) 293 [36], which do not express endogenous matriptase-2, and HepG2 cells (hepatocellular carcinoma, human) expressing matriptase-2 were cultured in Dulbecco's modified Eagle's medium (DMEM), supplemented with penicillin $(100 \mathrm{U} / \mathrm{ml})$, streptomycin $(100 \mu \mathrm{g} / \mathrm{ml})$, glutamine $(0.2 \mathrm{M}$; all substances from Invitrogen) and fetal bovine serum $(10 \%(\mathrm{v} / \mathrm{v}) ;$ FBS; PAA) under a humidified atmosphere of $5 \% \mathrm{CO}_{2}$ at $37^{\circ} \mathrm{C}$.

\section{Cloning and transfection}

Total mRNA was isolated from HepG2 cells expressing endogenous matriptase-2 with TRIZOL $^{\circledR}$ Reagent (Invitrogen) and transcribed into cDNA using Omniscript RT kit (Qiagen) and Oligo dT primer (Invitrogen) according to the instruction manuals. For construction of the cloning vector pDrivematriptase-2, TMPRSS6 cDNA was obtained by PCR using primers matriptase-2-fw (5'GCTCCCGGTACCATGCCCGTGGCCGAGGCCC-3') and matriptase-2-rv (5'GCTCCCCTCGAGGGTCACCACTTGCTGGATCC-3; Acc65I and XhoI recognition sites in bold, TMPRSS6 cDNA underlined) and ligated into the cloning vector pDrive (Qiagen). This vector was directly used to generate the expression plasmids pcDNA4-matriptase-2-Myc-His A and pcDNA4matriptase-2-His A or it was subjected to site directed mutagenesis with Gene Tailor ${ }^{\mathrm{TM}}$ Site-Directed Mutagenesis System (Invitrogen) according to the instruction manual using primers S753A-fw (5AGGATGCCTGTCAGGGTG-ACGCAGGTGGTCCG-3') and S753A-rv (5'-TCACCCTGACAGGCATCCTTCTTGCCCTTG-3'), R437E-fw (5'-CCCTCACCGGGCCCGGTGTGGAGGTGCACTATG-3') and R437E-rv (5'-CACACCGGGCCCGGTGAGGGAGATCTGGGAG-3'), R404E-fw (5'CAGGAGGCTGTGTGGCTTGGAGATCCTGCAGC-3') and R404-rv (5'-CAAGCCACACAGCCTCCTGTTCTGGATCGT-3') generating pDrive-matriptase-2-S753A, pDrive-matriptase-2-R437E and pDrive-matriptase-2-R404E. After their cloning into the Acc65I/XhoI restriction sites of expression plasmids pcDNA4-Myc-His A (Invitrogen), pcDNA4-His A or pcDNA4-Myc A, the TMPRSS6 cDNA fragments were confirmed by sequencing. The last two mentioned expression vectors were generated by AgeI/PmeI or respective Bst $\mathrm{BI}$ restriction of pcDNA4-Myc-His A to remove one of the tag. The resulting expression vectors pcDNA4-matriptase-2-Myc-His A, pcDNA4-matriptase-2-S753A-Myc-His A, pcDNA4-matriptase-2-R437E-Myc-His A， pcDNA4-matriptase-2-R404E-Myc-His A, pcDNA4matriptase-2-His A and pcDNA4-matriptase-2-S753A-Myc A encode the unmutated or mutated matriptase-2 protein tagged at the C-terminus with a c-Myc epitope (c-Myc-tag) and/or six histidine residues (His-tag). The expression vector pcDNA4-matriptase-2-R404E-R437E-Myc-His A was generated by restriction of pcDNA4-matriptase-2-R437E-Myc-His A and pcDNA4-matriptase-2-R404EMyc-His A with BglII followed by ligation.

HEK293 cells were stably transfected with these pcDNA4-vectors harbouring unmutated or mutated TMPRSS6 cDNA or the empty vector pcDNA4-Myc-His A by lipofection with Lipofectamine ${ }^{\mathrm{TM}} 2000$ (Invitrogen) according to the manufacturer's instructions to generate $\mathrm{MT}_{2}{ }^{\mathrm{WT}}-\mathrm{Myc}-\mathrm{His}, \mathrm{MT} 2^{\mathrm{S} 753 \mathrm{~A}}-\mathrm{Myc}-$

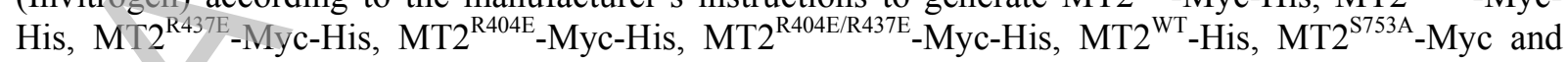
mock cells. Forty-eight hours after transfection, HEK293 cells were selected with Zeocin $(100 \mu \mathrm{g} / \mathrm{ml}$; Cayla SAS). Single cell clones were raised and selected for their ability to produce matriptase-2 protein 
by western blot analysis as described below. For the generation of co-transfected $\mathrm{MT} 2^{\mathrm{WT}}-\mathrm{His} / \mathrm{MT} 2^{\mathrm{S} 753 \mathrm{~A}}$ Myc cells, single-transfected MT2 ${ }^{\text {S753A }}$-Myc cells were transiently transfected with pcDNA4-matriptase2-His A. HEK293 cells transfected with the empty vector (mock cells) were checked by PCR analysis after genomic DNA preparation (PureLink ${ }^{\mathrm{TM}}$ Genomic DNA Mini Kit, Invitrogen).

\section{Immunocytochemistry}

Transfected MT2 ${ }^{\mathrm{WT}}$-Myc-His, MT2 ${ }^{\mathrm{S} 753 \mathrm{~A}}$-Myc-His and mock cells were cultured on poly-L-lysine-coated coverslips for two days. Cells were washed twice with ice-cold PBS and fixed in $4 \%(\mathrm{w} / \mathrm{v})$ paraformaldehyde in PBS for 30 min at room temperature followed by three washing steps with PBS. For permeabilization, cells were incubated with $0.1 \%(\mathrm{v} / \mathrm{v})$ triton $\mathrm{X}-100$ in $\mathrm{PBS}$ for $10 \mathrm{~min}$ at room temperature followed by two washing steps with PBS. Unspecific binding sites were blocked by incubation with 5\% (w/v) BSA (Carl Roth) in PBS for $1 \mathrm{~h}$ at room temperature, followed by incubation with monoclonal mouse anti-c-Myc antibody (clone 9E10 [37]; Sigma-Aldrich, 1:1000) in 2.5\% BSA in PBS for $1 \mathrm{~h}$ at room temperature. After three washing steps with PBS, cells were incubated with speciesspecific Alexa 594-conjugated secondary antibodies diluted 1:500 in 2.5\% BSA in PBS (goat anti-mouse IgG; Invitrogen) and with DAPI (4',6'-diamidino-2-phenylindole, $10 \mathrm{ng} / \mathrm{ml}$, nuclear staining) for $1 \mathrm{~h}$ at room temperature followed by three washing steps with PBS and a further washing step with distilled water. Cover slips were mounted with immumount (Shandon). For hardening, slides were stored over night at $4{ }^{\circ} \mathrm{C}$. Fluorescence signals were recorded with a Zeiss Axiovert 200 microscope equipped with a CCD camera.

\section{Cell fractionation and protein isolation}

Transfected MT2 ${ }^{\mathrm{WT}}$-Myc-His, MT2 ${ }^{\mathrm{R} 437 \mathrm{E}}$-Myc-His, MT2 ${ }^{\mathrm{R} 404 \mathrm{E}}-\mathrm{Myc}-\mathrm{His}, \mathrm{MT}^{\mathrm{R} 404 \mathrm{E} / \mathrm{R} 437 \mathrm{E}}-\mathrm{Myc}-\mathrm{His}, \mathrm{MT} 2^{\mathrm{WT}}$ His, MT2 $2^{\mathrm{S} 753 \mathrm{~A}}-\mathrm{Myc}, \mathrm{MT} 2^{\mathrm{WT}}$-His/MT2 ${ }^{\mathrm{S} 753 \mathrm{~A}}$-Myc and mock cells were seeded into $25 \mathrm{~cm}^{2}$-flasks $\left(5 \times 10^{5}\right.$ cells $/ \mathrm{cm}^{2}$ ) and cultured for one day in full media. The media were then replaced with FBS-free OptiMEM after two washing steps with PBS. Cells were cultured for another two days to increase protein concentration. After that, conditioned media were collected and concentrated using Amicon Ultra-15 Centrifugal Filters (3,000 MWCO, Millipore) and directly used for western blot analysis and enzyme activity measurements after protein quantification with Roti®-Nanoquant (Carl Roth).

For isolation of cellular membranes, HEK293 cells were washed three times with PBS and scraped off with $1 \mathrm{ml}$ of ice-cold buffer $\left(10 \mathrm{mM} \mathrm{KCl}, 1.5 \mathrm{mM} \mathrm{MgCl}_{2}, 1 \mathrm{mM}\right.$ EDTA, $1 \mathrm{mM}$ EGTA, $20 \mathrm{mM}$ Hepes, $\mathrm{pH}$ 7.5) followed by homogenization via ten aspirations through a 23-gauge needle. Intact cells and nuclei were removed by centrifugation $\left(2,000 \mathrm{~g}, 5 \mathrm{~min}, 4{ }^{\circ} \mathrm{C}\right)$. The resulting supernatants were centrifuged for one hour at $21,000 \mathrm{~g}$ and $4{ }^{\circ} \mathrm{C}$. Pellets containing cellular membranes were resuspended in $50 \mu \mathrm{l}$ buffer and total protein was quantified. For measurements of proteolytic activity, the pellet fractions were supplemented with $0.5 \%(\mathrm{v} / \mathrm{v}) \mathrm{NP} 40$ to solubilize membrane proteins.

For analysis of N-glycosylations of matriptase-2, samples obtained from insoluble cell fractions or conditioned media were treated with N-glycosidase F (PNGase F, New England Biolabs) following the instructions of the manufacturer.

\section{Western blotting}

For detection of matriptase-2, $10 \mu \mathrm{g}$ total protein of cellular membranes, cytosolic cell fractions and conditioned media were diluted in non-reducing or reducing (supplemented with $2 \%(\mathrm{v} / \mathrm{v}) 2$ mercaptoethanol) SDS-loading buffer and separated by SDS-PAGE on 10\% (w/v) polyacrylamide gels. Separated proteins were transferred onto nitrocellulose membrane (Schleicher \& Schuell). Transfer efficiency was determined by Ponceau S staining. Nitrocellulose membranes were blocked by incubation with 5\% (w/v) non-fat dried milk (Carl Roth) in PBST (PBS with 0.2\% (v/v) Tween-20) for $1 \mathrm{~h}$ at room 
temperature. Antigens were detected by incubation with monoclonal mouse anti-c-Myc antibody (clone 9E10 [37]; Sigma-Aldrich; 1:5000) or monoclonal mouse anti-His antibody (Invitrogen; 1:5000) for $1 \mathrm{~h}$ at room temperature. After three washing steps with PBST, primary antibody was incubated with speciesspecific alkaline phosphatase-conjugated secondary antibody diluted 1:10,000 in PBST (goat anti-mouse $\mathrm{IgG}$; Calbiochem) followed by three washing steps with PBST and one washing step with PBS. Resulting antigen-antibody complexes were detected with NBT/BCIP (nitro tetrazolium blue chloride/5-bromo-4chloro-3-indolyl phosphate, Sigma).

\section{Purification, mass spectrometry and N-terminal sequencing of shed matriptase-2}

The catalytic domain of matriptase- 2 was isolated from the concentrated conditioned medium of transfected MT2 ${ }^{\mathrm{WT}}$-Myc-His cells by immunoaffinity chromatography using ProFound ${ }^{\mathrm{TM}}$ c-Myc Tag IP/Co-IP Kit (Pierce Biotechnology, Rockford, USA) following the manufacturer's instructions. Purity of isolated matriptase- 2 was confirmed by SDS-PAGE. Protein bands representing purified matriptase-2 were extracted from reduced SDS-Gels and analyzed by LC-MS/MS by the bioanalytic service centre at the Centre of Molecular Medicine Cologne. The N-terminal sequence of the shed form of matriptase-2 was determined after blotting to PVDF membrane (Schleicher \& Schuell) using Edman degradation (Proteome Factory).

\section{Enzyme activity assay and kinetics}

Proteolytic activity of matriptase- 2 was measured with 1 to $20 \mu \mathrm{g}$ total protein of concentrated conditioned media and of membranes of transfected HEK293 cells prepared as described above. Activity was assayed according to Kolp et al. [38] in pre-warmed Tris saline buffer (50 mM Tris, $150 \mathrm{mM} \mathrm{NaCl}$, $\mathrm{pH} 8.0$ ) at $37^{\circ} \mathrm{C}$ by monitoring the release of $p$-nitroaniline from the chromogenic substrate N-Boc-GlnAla-Arg-p-nitroanilide ( $400 \mu \mathrm{M}$; Bachem) at a wavelength of $405 \mathrm{~nm}$ for up to $20 \mathrm{~min}$ using a Cary 100 UV-Vis spectrophotometer (Varian). Inhibition assays were performed either with $10 \mathrm{mM}$ of the metalloprotease inhibitor EDTA (Carl Roth) or with the serine protease inhibitors aprotinin and leupeptin (Carl Roth). Kinetic analysis was performed using GraFit version 5.0.

\section{RESULTS AND DISCUSSION}

\section{Expression of human matriptase-2 in HEK293 cells}

TTSPs are cell surface transmembrane proteins undergoing complex processing events. To examine subcellular localization of human matriptase-2, HEK293 cells were stably transfected with cDNA encoding human wild type matriptase- 2 (MT2 $\left.{ }^{\mathrm{WT}}-\mathrm{Myc}-\mathrm{His}\right)$ or the proteolytically inactive variant of matriptase-2 (MT2 ${ }^{\mathrm{S} 753 \mathrm{~A}}$-Myc-His). Both expressed constructs contain a C-terminal c-Myc-tag and a Histag. As obtained by immunofluorescence analysis permeabilized $\mathrm{MT} 2^{\mathrm{WT}}-\mathrm{Myc}-\mathrm{His}$ and $\mathrm{MT} 2^{\mathrm{S753A}}$-Myc-His cells revealed intracellular localization of matriptase-2 (Figures 1A and $1 \mathrm{C}$ ). To analyze the membrane localization of matriptase-2, non-permeabilized cells were used and a membrane staining was detected in $\mathrm{MT}^{\mathrm{WT}}$-Myc-His and MT2 ${ }^{\mathrm{S} 753 \mathrm{~A}}$-Myc-His cells (Figure 1B and 1D). The level of matriptase-2 at the cell surface of MT2 $2^{\mathrm{S} 753 \mathrm{~A}}-\mathrm{Myc}$-His cells was lower (Figure 1B), which was confirmed by immunoblot analysis when comparing the signals for matriptase- 2 in membrane fractions of MT2 ${ }^{\mathrm{WT}}-\mathrm{Myc}-\mathrm{His}$ and MT2 $2^{\mathrm{S} 753 \mathrm{~A}}$ Myc-His cells (Figure 2A, MT2). These data indicate the extracellular localization of the C-terminus of matriptase-2, consistent with the predicted cell membrane orientation of TTSPs [28-30]. In contrast, no signal was detectable within HEK293 cells transfected with pcDNA4-Myc-His A (mock) confirming the specificity of the immunofluorescence signals (Figures $1 \mathrm{E}$ and $1 \mathrm{~F}$ ). These data were in agreement with results previously described $[1,21,32]$ and were generated to prove the effectiveness of the cell model used for the investigation of human matriptase-2. 


\section{Identification of membrane-bound and shed forms of matriptase-2}

Membrane localization, as observed in immunofluorescence experiments, was confirmed by immunoblot analysis of isolated membranes derived from MT2 ${ }^{\mathrm{WT}}$-Myc-His cells. As shown in Figure 2A, matriptase-2 was visualized in membrane fractions of MT2 ${ }^{\mathrm{WT}}$-Myc-His cells as a single band of approximately 120 $\mathrm{kDa}$ (MT2) under reducing conditions. This is consistent with the calculated molecular mass of $88.9 \mathrm{kDa}$ for human matriptase-2, as well as expected N-linked glycosylations [1] and both tags because treatment of the cellular membrane fraction with PNGase F resulted in a shift of the $120 \mathrm{kDa}$-fragment to a protein band with a molecular mass similar to the calculated mass of matriptase-2 (Figures 2C and 2D, MT2). Under non-reducing conditions the same immunoreactive signal of approximately $120 \mathrm{kDa}$ was detected in membranes of MT2 ${ }^{\mathrm{WT}}$-Myc-His cells (Figure 2B, MT2). Furthermore, signals at $>170 \mathrm{kDa}$ (Figure 2B, MT2 complex), which were not present under reducing conditions, indicated that matriptase-2 exists in membranes as homo- or heteromeric complexes, tethered by disulfide bonds. The first extracellular cysteine residue $\mathrm{Cys}^{141}$ of matriptase-2 remains intramolecularly unpaired (Figure 4D) as suggested by computational simulations with murine matriptase-2 [40] and thus may serve as a potential site for homoor heteromeric protein interactions via disulfide bonding. Matriptase was also described as existing in heteromeric complexes within cellular membranes but these interactions are non-covalent [15,27]. The protein interacting with matriptase was identified in membrane-bound complexes [27] as well as in complexes localized in the conditioned medium of breast cancer cells or in human milk as the cognate hepatocyte growth factor activator inhibitor HAI-1 [31]. Today it is known that beside HAI-1, also HAI-2 [41] and several serpins $[42,43]$ can form complexes with matriptase. Due to the size of the multimeric matriptase-2 form, various interacting partners are supposable, matriptase- 2 itself for example as a transactivator (see below), which was also assumed for matriptase [22,23,27].

It was postulated that activation of TTSPs occurs via a proteolytic cleavage converting the singlechain zymogen into a two-chain, activated form in which the catalytic domain is tethered by a disulfide bond to the cell membrane-anchored non-catalytic $\mathrm{N}$-terminus [28-30,44,45]. Therefore, after activation cleavage, the catalytic domain of matriptase- 2 is expected to be attached to the propeptide fragment via the postulated disulfide bond formed by the two conserved cysteine residues Cys ${ }^{559}$ and $\mathrm{Cys}^{679}$ which are localized within the activation domain and the catalytic domain. Although using reducing conditions, we were not able to visualize the expected cleavage product, i.e. the catalytic domain (MT2 cat), in membrane fractions, suggesting that matriptase-2 is present predominantly in an inactive, single-chain form in cellular membranes.

In contrast, conditioned media of $\mathrm{MT} 2^{\mathrm{WT}}$-Myc-His cells contain a matriptase- 2 variant with a molecular mass of approximately $30 \mathrm{kDa}$ similar to the predicted molecular mass of the catalytic domain (Figure 2A, MT2 cat). This finding suggests that matriptase-2 is released from the cell surface as described previously for matriptase [22,31]. PNGase F treatment showed no effect on the molecular mass of the $30 \mathrm{kDa}$-fragment (Figure 2C, MT2 cat) consistent with the lack of consensus N-glycosylation sites in the protease domain [1]. None of these signals were detectable in mock cells or in cytosolic fractions of transfected HEK293 cells (Figure 2A) demonstrating the specificity of the anti-c-Myc antibody.

\section{Selective activity of shed matriptase-2}

To analyze the catalytic activities of cell-associated and released variants of matriptase-2, we determined the hydrolysis rate of the substrate for trypsin-like proteases, N-Boc-Gln-Ala-Arg- $p$-nitroanilide, which is also suitable for matriptase-2 [1,39], in isolated membranes and conditioned media of transfected HEK293 cells. Significant proteolytic activity was detectable in conditioned media derived from MT2 ${ }^{\mathrm{WT}}$ Myc-His cells correlating with increasing amounts of total protein content. In contrast, only a weak proteolytic activity was detected in the membrane fractions of these cells (Figure 3A). 
It was concluded that all measured activity resulted from specific catalytic activity of overexpressed matriptase- 2 in transfected MT2 ${ }^{\mathrm{WT}}$-Myc-His cells, as we did not detect any activity in the conditioned media and membrane fractions of mock and of $\mathrm{MT}^{\mathrm{S}}{ }^{753 \mathrm{~A}}$-Myc-His cells, although matriptase-2 protein was detectable in membrane fractions of $\mathrm{MT}^{\mathrm{S} 753 \mathrm{~A}}-\mathrm{Myc}-\mathrm{His}$ cells (Figure 3C). Furthermore, enzyme activity in membrane fractions and conditioned media of $\mathrm{MT} 2^{\mathrm{WT}}$-Myc-His cells was inhibited by the general serine protease inhibitors aprotinin and leupeptin, and no significant inhibition of proteolytic activity by $2 \mathrm{mM}$ EDTA, a general inhibitor of metalloproteases, was observable (data not shown).

In order to analyze whether the higher proteolytic activity in the conditioned media of transfected $\mathrm{MT} 2{ }^{\mathrm{WT}}$-Myc-His cells, compared to that of membrane fractions, is due to a higher content of matriptase2 , we assessed the amount of the enzyme in isolated membranes and conditioned media by western blot analysis. Matriptase- 2 protein content did not differ significantly in membranes and conditioned media (Figures 3B and 3C). Thus, the higher proteolytic activity in the conditioned media of transfected HEK293 cells resulted from a higher specific activity of matriptase-2 (an average of $0.073 \mathrm{U} / \mathrm{mg}$ total protein in the conditioned medium compared to an average of $0.006 \mathrm{U} / \mathrm{mg}$ total protein in membrane fractions). When expressed in HEK293 cells, matriptase also showed a higher specific activity in the conditioned medium than in membrane fractions [46]. These data indicate that cellular membranes mainly contain the inactive variant of matriptase- 2 correlating with the finding that no active, two-chain matriptase- 2 form was detectable in membranes by western blot analysis. The detection of the weak proteolytic activity in membranes might be due to a weak intrinsic proteolytic activity of single-chain TTSPs [30], which is important for autoactivation as mentioned below and which was also described for non-activated matriptase $[23,44,47]$. Moreover, the concentration of the activated enzyme in membranes might be too low for detection by immunoblotting, probably due to a continuous and rapid cell surface shedding.

\section{Shedding requires proteolytic processing within the stem region}

The isolation of soluble forms of TTSPs [31,48-50] suggests that the extracellular domain of at least some of them may be released from the cell surface. In agreement with recently published data on nonspecified, shed forms of matriptase- 2 in the conditioned medium of transiently transfected HeLa and HepG2 cells $[21,32,34,35]$, we have shown that a trypsin-like proteolytic activity exerted by matriptase-2 was predominantly found in the conditioned media. In order to characterize the released matriptase-2 form in the conditioned media of MT2 $2^{\mathrm{WT}}$-Myc-His cells in more detail, we performed western blot analysis after non-reducing SDS-PAGE. Interestingly, under these conditions a $55 \mathrm{kDa}$-fragment was detected (Figure 2B, MT2 shed) instead of a $30 \mathrm{kDa}$ immunoreactive band under reducing conditions (Figure 2A, MT2 cat). These data suggest that the shed form of matriptase-2 represents an active, twochain form in which the catalytic domain of matriptase- 2 is either linked to the non-catalytic N-terminal part (stem region) via the conserved disulfide bond, which was described previously for matriptase [22]. Alternatively, the catalytic domain is released in a dimeric form as proposed by Silvestri et al. [21].

To assess both possibilities, we isolated the released $55 \mathrm{kDa}$-form of matriptase- 2 from the conditioned media of MT2 ${ }^{\text {WT }}$-Myc-His cells by the use of immunoaffinity chromatography. After binding of matriptase-2 to the immobilized anti-c-Myc antibody and several washing steps, matriptase-2 was eluted and the purity was confirmed subsequently by SDS-PAGE. Coomassie staining revealed the presence of a single protein fragment of $55 \mathrm{kDa}$ after non-reducing SDS-PAGE (Figure 4A), whereas two fragments of approximately 45 and $30 \mathrm{kDa}$ were visualized under reducing conditions (Figure 4B). These findings strongly suggest that the catalytic domain of matriptase- 2 is shed into the surrounding medium bound to a part of the stem region as described for matriptase [22]. Furthermore, we analyzed the two different fragments, visualized by SDS-PAGE under reducing conditions, by LC-MS/MS. Analysis of the $30 \mathrm{kDa}$-fragment revealed peptides matching the catalytic domain of matriptase- 2 with a sequence 
identity of approximately $60 \%$ (Figure 4C). MS analysis of the $45 \mathrm{kDa}$-fragment indicated that this fragment consists of peptides of the three LDLRA domains and the N-terminal part of the activation site. Therefore, the shed $55 \mathrm{kDa}$-fragment (MT2 shed), visualized under non-reducing conditions, represents the activated, two-chain fragment in which the $30 \mathrm{kDa}$-serine protease domain (MT2 cat) is linked to a 45 $\mathrm{kDa}$-part of the stem region via disulfide bonding (Figure 4D). The inconsistency of the molecular masses of these fragments ( $55 \mathrm{kDa}$ as the sum of 30 and $45 \mathrm{kDa}$ ) can be explained by the observation that under non-reducing conditions the proteins seem to have a lower molecular mass due to the specific folding of the proteins under these conditions which has also been described for other TTSPs [15,31,51].

These findings were confirmed by one additional experiment. In contrast to published data [21], PNGase F treatment of the conditioned media lowered the molecular mass of the released $55 \mathrm{kDa}-$ fragment under non-reducing conditions to approximately $36 \mathrm{kDa}$ (Figure 2D, MT2 shed), indicating that this fragment is composed of a part of the stem region because only the stem region harbours possible Nglycosylation sites [1]. The minor band of $30 \mathrm{kDa}$ in the same lane represents the catalytic domain cleaved from the stem region because the samples were pretreated with buffer containing dithiothreitol prior to PNGase F addition (MT2 cat). Taken together, the cleavage site for the release of matriptase-2 from the cell surface must be located within the stem region.

\section{Identification of the shedding sequences}

To determine the positions of the processing sites of matriptase-2, the $30 \mathrm{kDa}$ - and $45 \mathrm{kDa}$-fragments isolated from the conditioned medium of transfected HEK 293 cells by immunoaffinity chromatography and subsequent reducing SDS-PAGE were each subjected to N-terminal amino acid sequencing. The 30 $\mathrm{kDa}$-fragment contains the amino acid sequence Ile ${ }^{568}$-Val-Gly-Gly-Ala representing the cleavage site between $\mathrm{Arg}^{567}$ and Ile ${ }^{568}$ within the activation motif, and the $45 \mathrm{kDa}$-fragment starts with the amino acid sequence Val ${ }^{438}$-His-Tyr-Gly-Leu-Tyr-Asn-Gln at its N-terminus (Figure 4C). This reveals the cleavage site after $\mathrm{Arg}^{437}$ lying within the stem region at the C-terminal end of the second CUB domain confirming the results obtained by mass spectrometry. The $45 \mathrm{kDa}$-fragment must be extensively $\mathrm{N}$-glycosylated as predicted by computational analysis, because this part comprises only 130 amino acids but has an apparent molecular mass of $45 \mathrm{kDa}$. Notably, both cleavages occur after arginine residues consistent with the substrate preference of matriptase- 2 for a basic amino acid in the P1 position [1,39] representing a first hint that matriptase-2 itself might be involved.

To verify that the peptide bond after $\operatorname{Arg}^{437}$ is indeed the cleavage site required for cell surface release of matriptase-2, we generated MT2 ${ }^{\mathrm{R} 437 \mathrm{E}}$-Myc-His cells expressing a mutant variant of matriptase- 2 in which $\mathrm{Arg}^{437}$ was exchanged for glutamate. As shown in Figure 5A the catalytic domain of the mutant variant of matriptase-2 was detected in the conditioned medium after reducing SDS-PAGE (MT2 cat) indicating that mutation of $\mathrm{Arg}^{437}$ did not prevent the shedding process per se. However, a fragment of approximately $57 \mathrm{kDa}$, larger than the shed form of wild type matriptase-2, was visualized in the conditioned medium by immunoblotting after non-reducing SDS-PAGE (Figure 5B, MT2 shed) demonstrating that cleavage after amino acid 437 was inhibited if no arginine is present and that more than one shedding sequences are supposable. This unknown cleavage site must be located at the Nterminal side of $\mathrm{Arg}^{437}$ because this position represents the final processing site leading to the smallest, two-chain form of matriptase-2 of $55 \mathrm{kDa}$ present in the conditioned medium. Because the shedding process is an autocatalytic process (see below), we generated HEK293 mutants expressing matriptase-2 variants with mutations of different arginine residues N-terminal of $\mathrm{Arg}^{437}$. As shown in Figure 5B, the conditioned medium of $\mathrm{MT}^{\mathrm{R} 404 \mathrm{E}}$-Myc-His cells revealed the $55 \mathrm{kDa}$-fragment (MT2 shed) representing the released form produced by cleavage after $\mathrm{Arg}^{437}$. Surprisingly, only a weak signal at $30 \mathrm{kDa}$ was detectable in the conditioned media of these cells under reducing conditions (Figure 5A, MT2 cat) indicating that activation was affected. In contrast, no fragments were found in the conditioned medium 
of the double mutant cells MT2 $2^{\mathrm{R} 404 \mathrm{E} / \mathrm{R} 437 \mathrm{E}}$-Myc-His under both conditions (Figure 5A and 5B). Altogether, these findings show that cell surface release of matriptase- 2 in HEK cells occurs by cleavage after $\mathrm{Arg}^{404}$ or $\mathrm{Arg}^{437}$ within the second CUB domain which is in contrast to a recent report of Ramsay et al. [32] who assumed that the released form of matriptase- 2 is generated by cleavage at Gly ${ }^{81}$ located within the SEA domain. Nevertheless, future investigations are needed to analyze whether N-terminal processing without cell surface release occurs as described for matriptase at the corresponding Gly ${ }^{81}$ of matriptase-2 $[23,25,26]$. Interestingly, the localization of the two shedding sequences of matriptase- 2 differs from that described for matriptase. Matriptase can be shed by proteolytic cleavage after two lysine residues between the SEA domain and the first CUB domain [22] whereas matriptase-2 is released without the two CUB domains.

Furthermore, shedding and activation need to be discussed with respect to their sequence of action which was done for matriptase [47]. Because in membrane fractions of MT2 ${ }^{\mathrm{R} 404 \mathrm{E} / \mathrm{R} 437 \mathrm{E}}-\mathrm{Myc}-\mathrm{His}$ cells predominantly single-chain zymogen was found, shedding seems to be the first step in the proteolytic processing of matriptase-2. Therefore, apart from its intrinsic activity, matriptase-2 is inactive on the cell surface as shown in Figure 3, and conversion of the single-chain zymogen into the two-chain protease might occur immediately after shedding. Then, the intrinsic activity of the zymogen must be sufficient for shedding and activation which was also published for the activation of matriptase [47].

\section{Shedding and activation requires catalytically active matriptase-2}

In order to investigate the requirement of matriptase-2 activity for shedding and activation cleavage, i.e. whether both processing events are autocatalyzed, we examined HEK293 cells transfected with cDNA encoding the inactive variant of matriptase- 2 in which the catalytic triad $\mathrm{Ser}^{753}$ was exchanged for alanine tagged with the c-Myc epitope. Immunoblot analysis revealed a $120 \mathrm{kDa}$-fragment in isolated membrane fractions of $\mathrm{MT}^{2753 \mathrm{~A}}$-Myc cells under both reducing (Figure 6A, MT2) and non-reducing conditions (data not shown) by the use of the anti-c-Myc antibody as observed for wild type matriptase- 2 of MT2 ${ }^{\mathrm{WT}}$ Myc-His cells. No derivatives of the mutated S753A variant were visible in the conditioned media of $\mathrm{MT} 2^{\mathrm{S} 753 \mathrm{~A}}$-Myc cells indicating that shedding was prevented. Additionally, activation was also inhibited, as a $30 \mathrm{kDa}$ fragment was absent in the conditioned media or membrane fractions of these cells (Figure 6A). Taking these data together, both processing events, shedding and activation cleavage, occur to be autocatalytic processes consistent with previous results on autoactivation of matriptase-2 expressed in bacteria [1]. In addition, matriptase underwent autoactivation cleavage, too [23,47] while for most other serine proteases the activation cleavage is facilitated by upstream proteases. This autoactivation mechanism allows matriptase and matriptase- 2 to serve as the most upstream proteases.

To analyze whether the autoactivation and/or autoshedding processes are catalyzed by the same (cismechanism) or by another (trans-mechanism) matriptase-2 molecule, we co-transfected HEK293 cells with two vectors, one expressing His-tagged wild type matriptase- 2 and one the c-Myc-tagged inactive S753A matriptase- 2 variant. No fragments were detectable in the conditioned medium of singletransfected MT2 ${ }^{\mathrm{S} 753 \mathrm{~A}}$-Myc cells as noted above. However, a weak signal was visualized in the conditioned medium of co-transfected MT2 ${ }^{\mathrm{WT}}$-His/MT2 ${ }^{\mathrm{S} 753 \mathrm{~A}}$-Myc cells using the anti-c-Myc antibody (Figure 6A, MT2 cat) indicating that the inactive S753A variant of matriptase-2 was shed into the surrounding medium. The released form was additionally processed by activation cleavage because the $30 \mathrm{kDa}-$ fragment (MT2 cat) appeared in the medium under reducing conditions. Therefore, shedding and activation cleavage of the c-Myc-tagged inactive S753A mutant form were catalyzed by His-tagged wild type matriptase- 2 suggesting a trans-mechanism in which the interaction between matriptase- 2 molecules leads to generation of a secreted, two-chain variant of matriptase-2. Notably, this is not a proximity driven process because activated S753A matriptase- 2 molecules were also detectable in the conditioned media of 
$\mathrm{MT} 2^{\mathrm{S} 753 \mathrm{~A}}$-Myc cells after the addition of conditioned media of MT2 ${ }^{\mathrm{WT}}$-His cells and incubation for two days (data not shown).

Expression of His-tagged wild type matriptase-2 in co-transfected $\mathrm{MT} 2^{\mathrm{WT}}-\mathrm{His} / \mathrm{MT} 2^{\mathrm{S753A}}-\mathrm{Myc}$ cells was confirmed by the use of the anti-His antibody (Figure 6B, MT2 and MT2 cat). Due to different numbers of tags on the shed matriptase- 2 fragments a shift of the molecular weight of the $30 \mathrm{kDa}-$ fragment was present in the conditioned media of the different transfected cells (Figure 6B, MT2 cat). No immunoreactive signals were detected neither in membrane fractions nor in the conditioned medium of single transfected MT2 ${ }^{\text {WT }}$-His cells using the anti-c-Myc antibody (Figure 6A) and in those fractions derived from $\mathrm{MT}^{\mathrm{S}}{ }^{\mathrm{M} 33 \mathrm{~A}}$-Myc cells using the anti-His antibody (Figure 6B).

In conclusion, we have demonstrated for the first time that human matriptase- 2 exists in noncomplexed and complexed forms localized in cellular membranes and characterized in detail the released portion of the protein in the extracellular space. We identified three proteolytic processing events of matriptase-2; two cleavages occur after $\mathrm{Arg}^{404}$ and $\mathrm{Arg}^{437}$ within the stem region which are important for cell surface release of matriptase- 2 and one after residue $\mathrm{Arg}^{567}$ located within the conserved activation site converting the single-chain zymogen into the activated, two-chain protease. Shedding seems to be the first step in the proteolytic processing of matriptase-2 because activation was prevented in HEK mutant cells (MT2 ${ }^{\mathrm{R} 404 \mathrm{E} / \mathrm{R} 437 \mathrm{E}}$-Myc-His) expressing a matriptase-2 variant which cannot be shed. This is consistent with the finding that matriptase-2 exerted its activity predominantly in the conditioned medium. Additionally, our data reveal that matriptase-2 undergoes shedding and activation via a trans-mechanism. 


\section{ACKNOWLEDGEMENT}

We thank Janna Rudolph for assistance.

\section{FUNDING}

This work was supported by Deutsche Forschungsgemeinschaft Grant SFB645 and by NRW International Graduate Research School Biotech-Pharma.

\section{REFERENCES}

1 Velasco, G., Cal, S., Quesada, V., Sánchez, L. M. and López-Otín, C. (2002) Matriptase-2, a membrane-bound mosaic serine proteinase predominantly expressed in human liver and showing degrading activity against extracellular matrix proteins. J. Biol. Chem. 277, 37637-37646

2 Leytus, S. P., Loeb, K. R., Hagen, F. S., Kurachi, K. and Dayie, E. W. (1988) A novel trypsin-like serine protease (hepsin) with a putative transmembrane domain expressed by human liver and hepatoma cells. Biochemistry 27, 1067-1074

3 Shi, Y. E., Torri, J., Yieh, L., Wellstein, A., Lippman, M. E. and Dickson, R. B. (1993) Identification and characterization of a novel matrix-degrading protease from hormone-dependent human breast cancer cells. Cancer Res. 53, 1409-1415

4 Kitamoto, Y., Veile, R. A., Donis-Keller, H. and Sadler, J. E. (1995) cDNA sequence and chromosomal localization of human enterokinase, the proteolytic activator of trypsinogen. Biochemistry 34, 4562-4568

5 Yamaoka, K., Masuda, K., Ogawa, H., Takagi, K., Umemoto, N. and Yasuoka, S. (1998) Cloning and characterization of the cDNA for human airway trypsin-like protease. J. Biol. Chem. 273, 11895-11901

6 Yan, W., Sheng, N, Seto, M., Morser, J. and Wu, Q (1999) Corin, a mosaic transmembrane serine protease encoded by a novel cDNA from human heart. J. Biol. Chem. 274, 14926-14935

7 Yamaguchi, N., Okui, A., Yamada, T., Nakazaot, H. and Mitsui, S. (2002) Spinesin/TMPRSS5, a novel transmembrane serine protease, cloned from human spinal cord. J. Biol. Chem. 277, 68066812

8 Szabo, R., Netzel-Arnett, S., Hobson, J. P., Antalis, T. M. and Bugge, T. H. (2005) Matriptase-3 is a novel phylogenetically preserved membrane-anchored serine protease with broad serpin reactivity. Biochem. J. 390, 231-242

9 Lin, C. Y., Anders, J., Johnson, M., Sang, Q. A. and Dickson, R. B. (1999) Molecular cloning of cDNA for matriptase, a matrix-degrading serine protease with trypsin-like activity. J. Biol. Chem. 274, 18231-18236

10 Overall, C. M., Tam, E. M., Kappelhoff, R., Connor, A., Ewart, T., Morrison, C. J., Puente, X., López-Otín, C. and Seth, A. (2004) Protease degradomics: mass spectrometry discovery of protease substrates and the CLIP-CHIP, a dedicated DNA microarray of all human proteases and inhibitors. Biol. Chem. 385, 493-504

11 Sanders, A. J., Parr, C., Davies, G., Martin, T. A., Lane, J., Mason, M. D. and Jiang, W. G. (2006) Genetic reduction of matriptase-1 expression is associated with a reduction in the aggressive phenotype of prostate cancer cells in vitro and in vivo. J. Exp. Ther. Oncol. 6, 39-48

12 Parr, C., Sanders, A. J., Davies, G., Martin, T., Lane, J., Mason, M. D., Mansel, R. E. and Jiang W. G. (2007) Matriptase-2 inhibits breast tumor growth and invasion and correlates with favorable prognosis for breast cancer patients. Clin. Cancer. Res. 13, 3568-3576

13 Sanders A. J., Parr, C., Martin, T. A., Lane, J., Mason, M. D. and Jiang W. G. (2008) Genetic upregulation of matriptase-2 reduces the aggressiveness of prostate cancer cells in vitro and in vivo and affects FAK and paxillin localisation. J. Cell. Physiol. 6, 780-789

14 Lee, S. L., Dickson, R. B. and Lin, C. Y. (2000) Activation of hepatocyte growth factor and urokinase/plasminogen activator by matriptase, an epithelial membrane serine protease. J. Biol. Chem. 275, 36720-36725

15 Takeuchi, T., Harris, J. L., Huang, W., Yan, K. W., Coughlin, S. R. and Craik, C. S. (2000) Cellular localization of membrane-type serine protease 1 and identification of protease-activated 
receptor-2 and single-chain urokinase-type plasminogen activator as substrates. J. Biol. Chem. 275, 26333-26342

16 Jin, X., Yagi, M., Akiyama, N., Hirosaki, T., Higashi, S., Lin, C. Y., Dickson, R. B., Kitamura, H. and Miyazaki, K. (2006) Matriptase activates stromelysin (MMP-3) and promotes tumor growth and angiogenesis. Cancer Sci. 97, 1327-1334

17 Uhland, K. (2006) Matriptase and its putative role in cancer. Cell. Mol. Life Sci. 63, 2968-2978

18 Finberg, K. E., Heeney, M. M., Campagna, D. R, Aydinok, Y., Pearson, H. A., Hartman, K. R., Mayo, M. M., Samuel S. M., Strouse, J. J., Markianos, K., Andrews, N. C. and Fleming, M. D. (2008) Mutations in TMPRSS6 cause iron-refractory iron deficiency anemia (IRIDA). Nat. Genet. 40, 569-571

19 Du, X., She, E., Gelbart, T., Truksa, J., Lee, P., Xia, Y., Khovananth, K., Mudd, S., Mann, N., Moresco, E. M., Beutler, E and Beutler, B. (2008) The serine protease TMPRSS6 is required to sense iron deficiency. Science 320, 1088-1092

20 Folgueras, A. R., de Lara, F. M., Pendás, A. M., Garabaya, C., Rodríguez, F., Astudillo, A., Bernal., T., Cabanillas, R., López-Otín, C and Velasco, G. (2008) Membrane-bound serine protease matriptase-2 (Tmprss6) is an essential regulator of iron homeostasis. Blood 112, 25392545

21 Silvestri, L., Pagani, A., Nai, A., De Domenico, I., Kaplan, J. and Camaschella, C. (2008) The serine protease matriptase-2 (TMPRSS6) inhibits hepcidin activation by cleaving membrane hemojuvelin. Cell Metabol. 8, 502-511

22 Benaud, C., Dickson, R. B. and Lin, C. Y. (2001) Regulation of the activity of matriptase on epithelial cell surfaces by a blood-derived factor. Eur. J. Biochem. 168, 1439-1447

23 Oberst, M. D., Williams, C A., Dickson, R. B., Johnson, M. D. and Lin, C. Y. (2003) The activation of matriptase requires its noncatalytic domains, serine protease domain, and its cognate inhibitor. J. Biol. Chem. 278, 26773-26779

24 Lin, C. Y., Tseng, I. C., Chou, F. P., Su, S. F., Chen, Y. W., Johnson, M. D. and Dickson, R. B. (2008) Zymogen activation, inhibition, and ectodomain shedding of matriptase. Front. Biosci. 13, 621-635

25 Tsuzuki, S., Murai, N., Miyake, Y. Inouye, K., Hirayasu, H., Iwanaga, T. and Fushiki, T. (2005) Evidence for the occurrence of membrane-type serine protease 1 /matriptase on the basolateral sides of enterocytes. Biochem. J. 388, 679-687

26 Kilpatrick, L. M., Harris, R. L., Owen, K. A., Bass, R., Ghorayeb, C., Bar-Or, A. and Ellis, V. (2006) Initiation of plasminogen activation on the surface of monocytes expressing the type II transmembrane serine protease matriptase. Blood 108, 2616-2623.

27 Lee, M. S., Kiyomiya, K., Benaud, C., Dickson, R. B. and Lin, C. Y. (2005) Simultaneous activation and hepatocyte growth factor activator inhibitor 1-mediated inhibition of matriptase induced at activation foci in human mammary epithelial cells. Am. J. Physiol. Cell Physiol. 288, C932-C941

$28 \mathrm{Wu}$, Q. (2003) Type II transmembrane serine proteases. Curr. Top. Dev. Biol. 54, 167-206

29 Szabo, R. and Bugge, T. H. (2008) Type II transmembrane serine proteases in development and disease. Int. J. Biochem. Cell Biol. 40, 1297-1316

30 Hooper, J. D., Clements, J. A., Quigley, J. P. and Antalis, T. M. (2001) Type II transmembrane serine proteases. Insights into an emerging class of cell surface proteolytic enzymes. J. Biol. Chem. 276, 857-860

31 Lin, C. Y., Anders, J., Johnson, M. and Dickson, R. B. (1999) Purification and characterization of a complex containing matriptase and a Kunitz-type serine protease inhibitor from human milk. J. Biol. Chem. 274, 18237-18242

32 Ramsay, A. J., Quesada, V., Sanchez, M., Garabaya, C., Sardà, M. P., Baiget, M., Remacha, A., Velasco, G. and López-Otín, C. (2009) Matriptase-2 mutations in iron-refractory iron deficiency anemia patients provide new insights into protease activation mechanisms. Hum. Mol. Genet. 18, 3673-3683

33 Tchou, I., Diepold, M., Pilotto, P. A., Swinkels, D., Neerman-Arbez, M. and Beris, P. (2009) Haematologic data, iron parameters and molecular findings in two new cases of iron-refractory iron deficiency anaemia. Eur. J. Haematol. 83, 595-602

34 De Falco, L., Totano, F., Nai, A., Pagani, A., Girelli, D., Silvestri, L., Piscopo, C., Campostrini, N., Dufour, C., Manjomi, F. A., Minkov, M., Van Vuurden, D. G., Feliu, A., Kattamis, A., 
Camaschella, C. and Iolascon, A. (2010) Novel TMPRSS6 mutations associated with ironrefractory iron deficiency anemia (IRIDA). Hum. Mutat. [Epub ahead of print]

35 Silvestri, L., Guillem, F., Pagani, A., Nai, A., Oudin, C., Silva, M., Toutain, F., Kannengiesser, C., Beaumont, C., Camaschella, C. and Grandchamp, B. (2009) Molecular mechanisms of the defective hepcidin inhibition in TMPRSS6 mutations associated with iron-refractory iron deficiency anemia. Blood 113, 5605-5608

36 Graham, F. L., Smiley, J, Russell, W. C. and Nairn, R. (1977) Characteristics of a human cell line transformed by DNA from human adenovirus type 5. J. Gen. Virol. 36, 59-74

37 Evan, G. I., Lewis, G. K., Ramsay, G. and Bishop, J. M. (1985) Isolation of monoclonal antibodies specific for human c-myc proto-oncogene product. Mol. Cell Biol. 5, 3610-3616

38 Kolp, S., Pietsch, M., Galinski, E. A. and Gütschow, M. (2006) Compatible solutes as protectants for zymogens against proteolysis. Biochim. Biophys. Acta 1764, 1234-1242

39 Béliveau, F., Désilets, A. and Leduc, R. (2009) Probing the substrate specificities of matriptase, matriptase-2, hepsin and DESC1 with internally quenched fluorescent peptides. FEBS J. 276, 2213-2226

40 Hooper, J. D., Campagnolo, L., Goodarzi, G., Truong, T. N., Stuhlmann, H. and Quigley, J. P. (2003) Mouse matriptase-2: identification, characterization and comparative mRNA expression analysis with mouse hepsin in adult and embryonic tissues. Biochem. J. 373, 689-702

41 Szabo, R., Hobson, J. P., List, K., Molinolo, A., Lin, C. Y. and Bugge, T. H. (2008) Potent inhibition and global co-localization implicate the transmembrane Kunitz-type serine protease inhibitor hepatocyte growth factor activator inhibitor-2 in the regulation of epithelial matriptase activity. J. Biol. Chem. 283, 29495-29504

42 Janciauskiene, S., Nita, I., Subramaniyam, D., Li, Q., Lancaster, J. R. Jr. and Matalon, S. (2008) Alpha1-antitrypsin inhibits the activity of the matriptase catalytic domain in vitro. Am. J. Respir. Cell Mol. Biol. 39, 631-637

43 Tseng, I. C., Chou, F. P., Su, S. F., Oberst, M., Madayiputhiya, N., Lee, M. S., Wang, J. K., Sloane, D. E., Johnson, M. and Lin, C. Y. (2008) Purification from human milk of matriptase complexes with secreted serpins: mechanism for inhibition of matriptase other than HAI-1. Am. J. Physiol. Cell Physiol. 295, C423-C431

44 Takeuchi, T. Shuman, M. A. and Craik, C. S. (1999) Reverse biochemistry: use of macromolecular protease inhibitors to dissect complex biological processes and identify a membrane-type serine protease in epithelial cancer and normal tissue. Proc. Natl. Acad. Sci. U. S. A. 96, 11054-11061

45 Kitamoto, Y., Yuan, X., Wu, Q., McCourt, D. W. and Sadler, J. E. (1994) Enterokinase, the initiator of intestinal digestion, is a mosaic protease composed of a distinctive assortment of domains. Proc. Natl. Acad. Sci. U. S. A. 91, 7588-7592

46 Désilets, A., Béliveau, F., Vandal., G., McDuff, F. O., Lavigne, P. and Leduc, R., (2008) Mutation G827R in matriptase causing autosomal recessive ichthyosis with hypotrichosis yields an inactive protease. J. Biol. Chem. 283, 10535-10542

47 Miyake, Y., Yasumoto, M., Tsuzuki, S., Fushiki, T. and Inouye, K. (2009) Activation of a membrane-bound serine protease matriptase on the cell surface. J. Biochem. 146, 273-282

48 Louvard, D., Maroux, S., Baratti, J. and Desnuelle, P. (1973) On the distribution of enterokinase in porcine intestine and on its subcellular localization. Biochim. Biophys. Acta 309, 127-137

49 Fonseca, P. and Light, A. (1983) Incorporation of bovine enterokinase in reconstituted soybean phospholipid vesicles. J. Biol. Chem. 258, 3069-3074

50 Yasouka, S., Ohnishi, Z., Kawano, S., Tsuchihashi, S., Ogawara, M., Yamaoka, K., Takahashi, M. and Sano, T. (1997) Purification, characterization, and localization of a novel trypsin-like protease found in the human airway. Am. J. Respir. Cell Mol. Biol. 16, 300-308

51 Knappe, S., Wu, F., Masikat, M. R., Morser, J. and Wu, Q. (2003) Functional analysis of the transmembrane domain and activation cleavage of human corin: design and characterization of a soluble corin. J. Biol. Chem. 278, 52363-52370 


\section{FIGURE LEGENDS}

\section{Figure 1 Subcellular localization of matriptase-2}

Immunofluorescence detection of matriptase-2 in transfected $\mathrm{MT}_{2}{ }^{\mathrm{WT}}$-Myc-His (A, B), MT2 ${ }^{\mathrm{S} 753 \mathrm{~A}}-\mathrm{Myc}-$ His $(\mathbf{C}, \mathbf{D})$ and mock cells $(\mathbf{E}, \mathbf{F})$ using monoclonal mouse anti-c-Myc antibody (red). Fluorescence was detected in cells permeabilized with $0.1 \%$ triton X-100 (A, C, E) and on the cell surface of nonpermeabilized cells $(\mathbf{B}, \mathbf{D}, \mathbf{F})$. Nuclei were stained with DAPI (blue; $10 \mathrm{ng}$ per $\mathrm{ml}$ ). The white scale bar represents $10 \mu \mathrm{m}$.

\section{Figure 2 Immunoblot analysis of matriptase-2 in transfected $\mathrm{MT}^{\mathrm{WT}}$-Myc-His cells}

MT2 ${ }^{\text {WT }}$-Myc-His, MT2 ${ }^{\text {S753A }}$-Myc-His and mock cells were cultured for two days with Opti-MEM and then fractionated as described. (A, B) $10 \mu \mathrm{g}$ total protein of conditioned media (CM), membrane fractions (MF) and cytosolic fractions (CF) were separated under reducing (A) and non-reducing (B) conditions. (C, D) For analysis of N-glycosylations $10 \mu \mathrm{g}$ total protein of conditioned media (CM) and membrane fractions (MF) of MT2 ${ }^{\mathrm{WT}}$-Myc-His cells were either preincubated with $(+)$ or without $(-)$ PNGase F and separated under reducing (C) and non-reducing (D) conditions. Samples were electroblotted onto nitrocellulose membranes and matriptase-2 protein was visualized using monoclonal mouse anti-c-Myc antibody. The dividing line (D) indicates the grouping of images from different parts of the same gel. The immunoblots shown are representative for three independent experiments. M, molecular mass marker; MT2, matriptase-2.

\section{Figure 3 Cell surface shedding of active matriptase-2}

(A) Different amounts of total protein of conditioned media (grey) and membrane fractions (black) of transfected MT2 $2^{\mathrm{WT}}$-Myc-His, MT2 ${ }^{\mathrm{S} 753 \mathrm{~A}}$-Myc-His and mock cells were incubated with $100 \mu \mathrm{M}$ N-BocGln-Ala-Arg- $p$-nitroanilide as a substrate. The release of the dye $p$-nitroaniline was monitored at a wavelength of $405 \mathrm{~nm}$ for up to $20 \mathrm{~min}$ at $37^{\circ} \mathrm{C}$ using a spectrophotometer. The resulting activities (one unit corresponds to a release rate of one pmole of $p$-nitroaniline per minute) were measured in two independent experiments in duplicates. (B, C) The amount of matriptase-2 protein in the conditioned media (B) and membrane fractions (C) of transfected HEK cells was estimated under reducing conditions by immunoblot analysis using anti-c-Myc antibody. Shown are representative blots of three independent experiments. The dividing line indicates the grouping of images. M, molecular mass marker.

\section{Figure 4 Purification and analysis of shed matriptase-2 from MT2 ${ }^{\mathrm{WT}}$-Myc-His cells}

MT2 ${ }^{\text {WT }}$-Myc-His cells were cultured for two days with Opti-MEM. Conditioned medium was concentrated and subjected to immunoaffinity chromatography using immobilized anti-c-Myc antibody to isolate the shed form of matriptase-2. (A, B) Purity of isolated matriptase-2 was confirmed by non-reducing (A) and reducing (B) SDS-PAGE followed by Coomassie staining. lane 1, flowthrough; lanes 2-4, wash fractions; lanes 5-6, elution fractions; M, molecular mass marker. (C) Amino acid sequence of human matriptase-2. Peptides derived from mass spectrometric analysis of the shed $30 \mathrm{kDa}$-fragment match the catalytic domain (underlined), peptides derived from mass spectrometric analysis of the shed $45 \mathrm{kDa}$-fragment match the stem region (bold underlined). The sequences estimated by Edman degradation are shown in bold, the cleavage sites are indicated by arrows. (D) Schematic representation of matriptase-2 with its domain organization. SEA, sea urchin sperm protein, enteropeptidase, agrin domain; CUB, complement factor $\mathrm{C} 1 \mathrm{~s} / 1 \mathrm{r}$, urchin embryonic growth factor, bone morphogenetic protein domain; L, low density lipoprotein receptor class A domain; N, putative $\mathrm{N}$-glycosylation site; $\mathrm{S}, \mathrm{Cys}^{141}$ representing a free cysteine residue; H, D, S, catalytic triad, MT2, matriptase-2. 


\section{Figure 5 Immunoblot analysis of matriptase-2 variants affected in the cell surface release}

MT2 ${ }^{\text {WT }}$-Myc-His, MT2 ${ }^{\text {R437E }}$-Myc-His, MT2 ${ }^{\text {R404E }}$-Myc-His and $\mathrm{MT}^{\mathrm{R} 404 \mathrm{E} / \mathrm{R} 437 \mathrm{E}}$-Myc-His cells were cultured for two days with Opti-MEM and then fractionated as described. $10 \mu \mathrm{g}$ total protein of conditioned media (CM) and membrane fractions (MF) were separated under reducing (A) and nonreducing (B) conditions and processed for western blot analysis using anti-c-Myc antibody. The immunoblots shown are representative for three independent experiments. $\mathrm{M}$, molecular mass marker; MT2, matriptase-2.

\section{Figure 6 Immunoblot analysis of catalytically inactive matriptase-2}

$\mathrm{MT}^{\mathrm{WT}}$-Myc-His, MT2 ${ }^{\mathrm{WT}}$-His, MT2 ${ }^{\mathrm{S} 753 \mathrm{~A}}$-Myc and co-transfected $\mathrm{MT} 2^{\mathrm{WT}}$-His/MT2 $2^{\mathrm{S} 753 \mathrm{~A}}$-Myc cells were cultured for two days with Opti-MEM and then fractionated as described. $10 \mu \mathrm{g}$ total protein of conditioned media (CM) and membrane fractions (MF) were separated under reducing conditions and processed for western blot analysis using anti-c-Myc antibody (A) or anti-His antibody (B). The immunoblots shown are representative for three independent experiments. $M$, molecular mass marker; MT2, matriptase-2. 
Figure 1
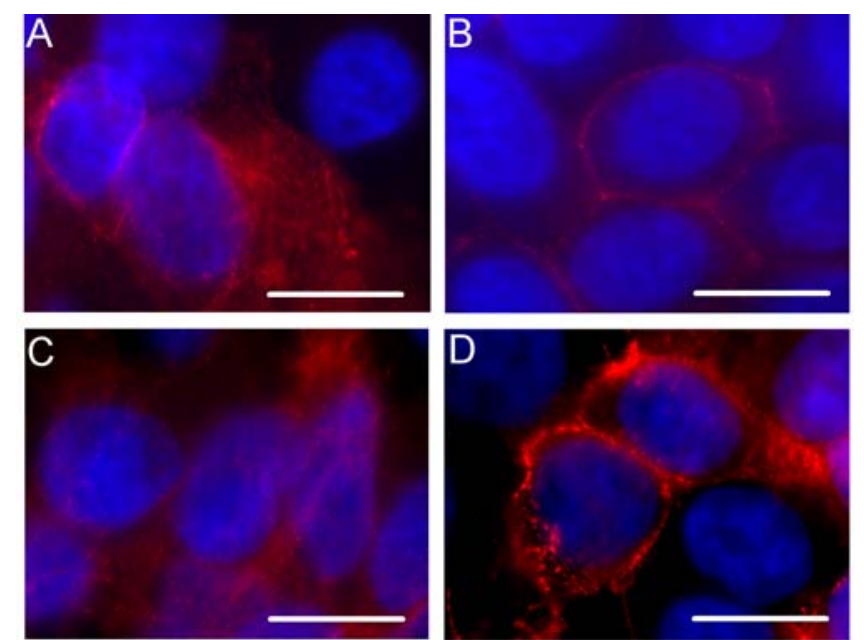

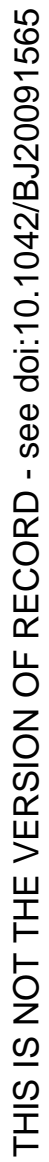

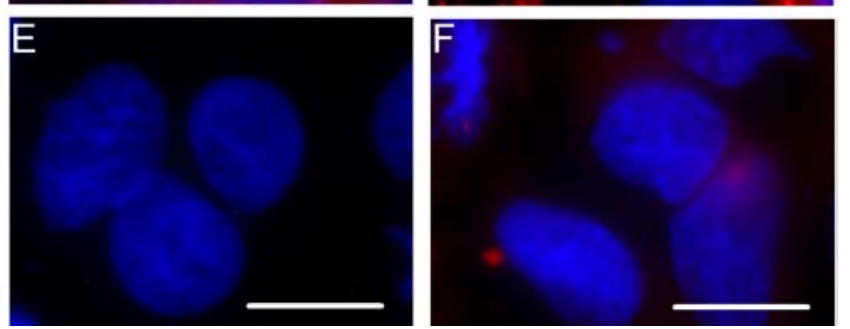


Figure 2

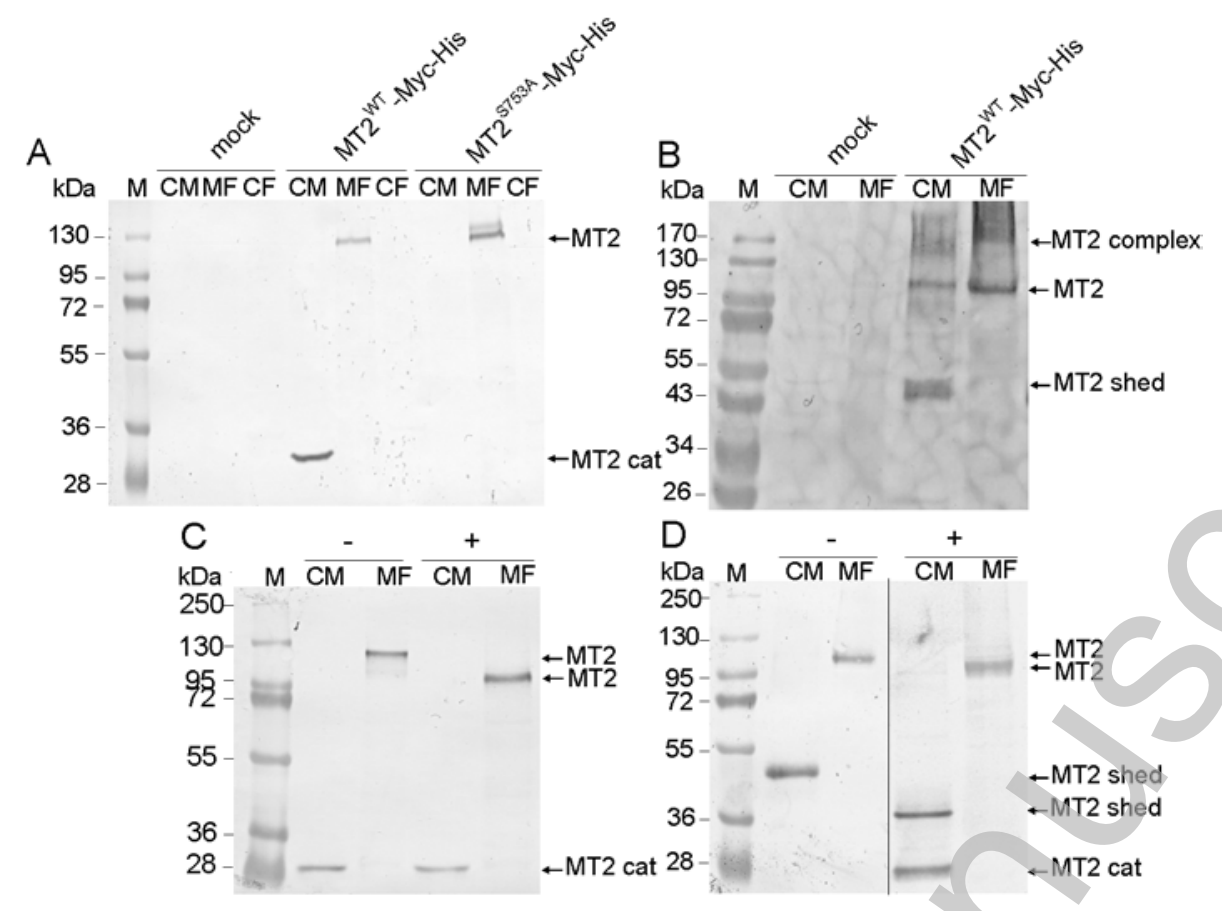


Figure 3

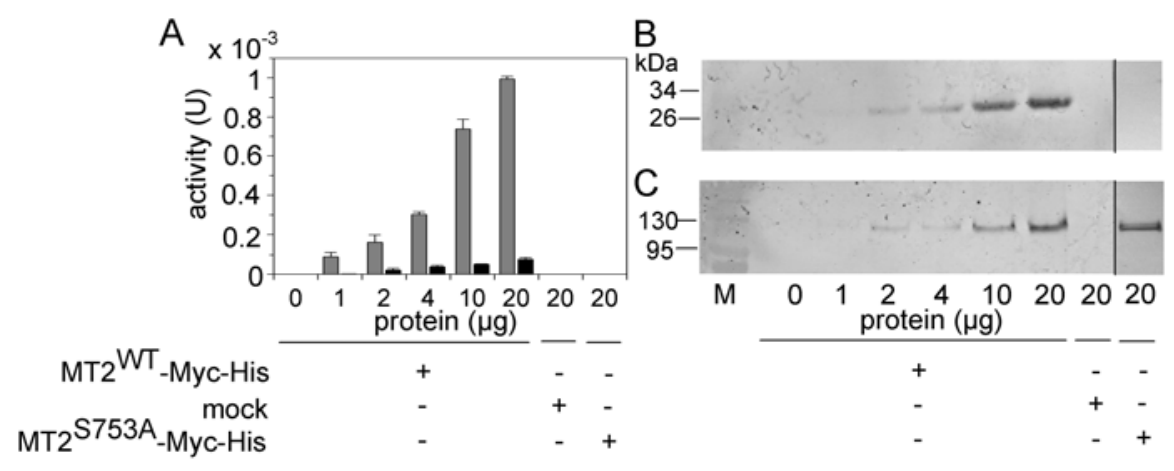


Figure 4

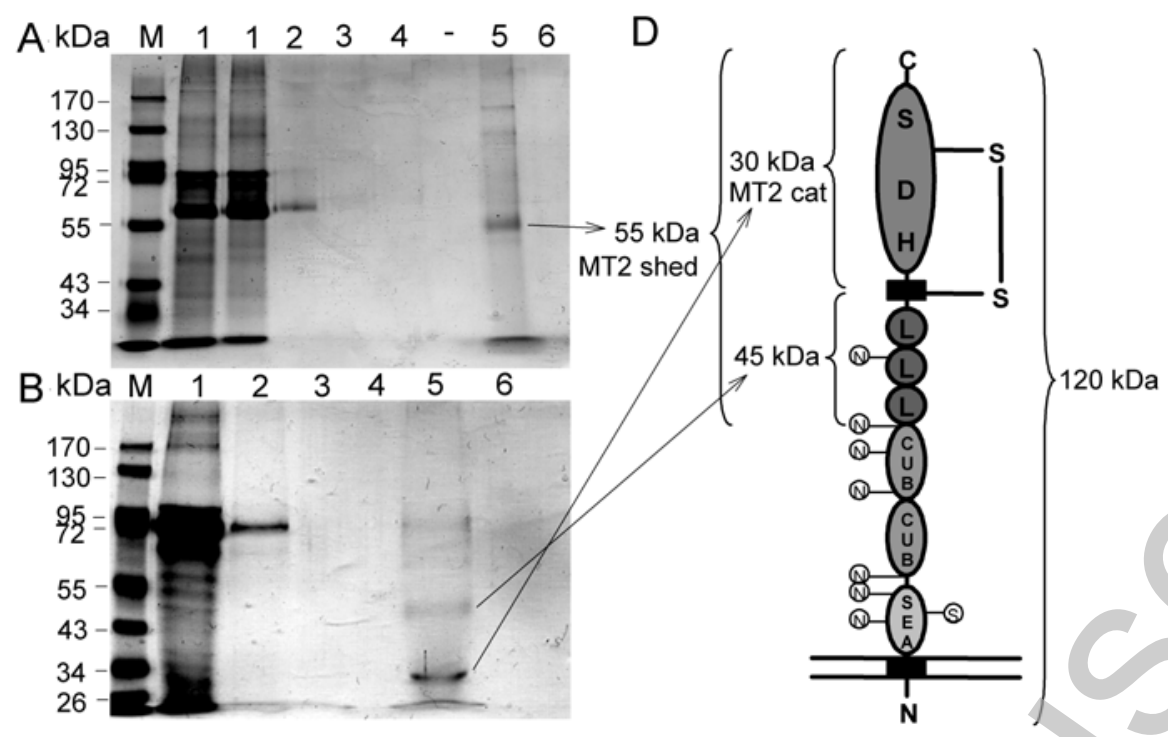

C

1 mpvaeapqva ggqgdggdge eaepegmfka cedskrkarg ylrlvplfvl lallvlasag 61 vllwyflgyk aevmvsqvys gslrvlnrhf sqditrress afrsetakaq kmlkelitst 121 rlgtyynsss vysfgegplt cffwfilqip ehrrlmlspe vvqallveel 1stvnssaav 181 pyraeyevdp eglvileasv kdiaalnstl gcyrysyvgq gqvlrlkgpd hlassclwhl 241 ggpkdlmlkl rlewtlaecr drlamydvag plekrlitsv ygcsrgepvv evlasgaima 301 vvwkkglhsy ydpfvlsvqp vvfqacevnl tldnrldsqg vlstpyfpsy yspqthcswh 361 ltvpsldygl alwfdayalr rqkydlpctq gqwtiqnrrl cglrilqpya eripvvatag 421 itinftsqis ltgpgvivhy glynqsdpcp geflcsvngl cvpacdgvkd cpnqlernc 481 vcratfqcke dstcislpkv cdgqpdclng sdeeqcqegv pcgtftfqce drscvkkpnp 541 qcdgrpdcrd gsdeehcdcg lggpss ivg gavssegewp wgaslqurgr hicggaliad 601 rwvitaahcf gedsmastvl wtvflqkvwg nsrwpgevsf kvsrllihpy heedshdydv 661 allqldhpvv rsaavrpvcl parshffepg lhcwitgwga lreggpisna lqkvdvqlip 721 gdlcsevyry qvtprmlcag yrkgkkdacq gdsggplvck alsgrwflag lvswglgcgr 781 pnyfgvytri tgviswiqqv vt 
B Biochemical Journal Immediate Publication. Published on 02 Jun 2010 as manuscript BJ20091565

Figure 5

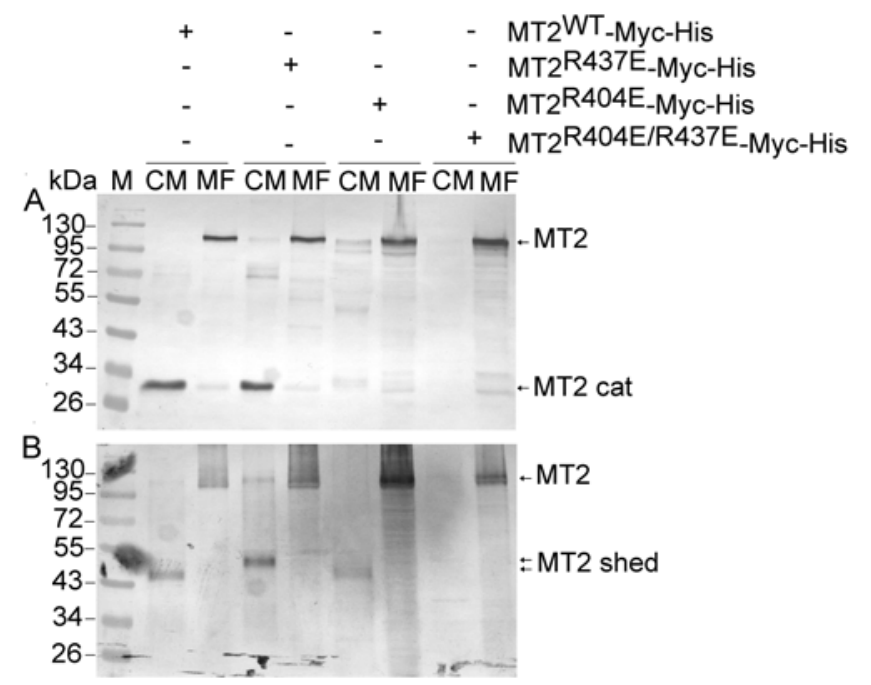


B Biochemical Journal Immediate Publication. Published on 02 Jun 2010 as manuscript BJ20091565

Figure 6

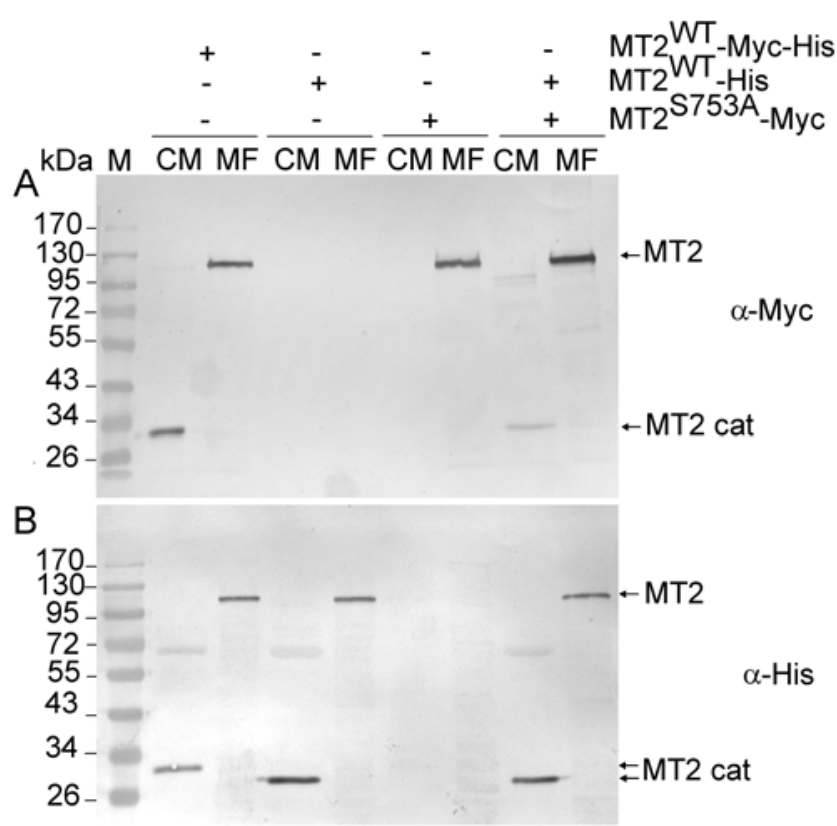

